(II) For the aggregate of Polynesian languages, taken together : (1) a comparative phonology, that is, something setting out all results of the Type AS. stān : MnE. stone (mentioned above); W. Streitberg, "Urgermanische Grammatik", might serve as a model ; (2) an etymological dictionary; A. Walde and J. Pokorny, "Vergleichendes Wörterbuch der Indogermanischen Sprachen", might serve as a model.

There is, finally, the question of selecting and training the proposed unit for the establishment of the comparative philology of Polynesian. All its members must, of course, be thoroughly conversant with comparative philology, and this end is probably best attained by their having passed through some quite conventional school of philology (such as 'English Language', 'French Language' or Sanskrit, as taught in Great Britain). Next they must have an adequate training in Indonesian, and this can only be gained by at least three years residence in Holland (and, possibly, some time in Indonesia). It is much to be hoped that at least one member of the unit will be a native speaker of Maori (one who had gone through an 'English Language' training in a New Zealand university would be ideal) ; it might well be desirable to invite a distinguished Dutch Indonesianist to spend at least some time as another member.

\section{CHEMICAL RESEARCH LABORATORY, TEDDINGTON REPORT FOR 1952}

\footnotetext{
T
}

HE report of the Chemistry Research Board, signed by the chairman, Prof. E. L. Hirst, and the report of the director of the Chemical Research Laboratory, Teddington, Dr. D. D. Pratt, make up the contents of "Chemistry Research 1952", which has recently been published*. To these reports are appended a list of more than fifty papers submitted for publication during the year, and lists of the staff of the Laboratory, of metals held by the Pure Metals Committee, of standard substances available and of species in the National Collection of Industrial Bacteria. Both reports refer to the improvement in working conditions through the occupation of the new Radiochemical Building in May and of the Microbiological Buildings in November, thus easing the overcrowded conditions in the main building and enabling the construction of a mass spectrometer and research on high-temperature corrosion of metals by hot flue gases and by boiler-water to be commenced. Nevertheless, the Board records the opinion that the scientific staff is still too small in relation to the programme, though it merely expresses the hope that additional staff will be provided "when circum. stances permit".

The Board's report again stresses the value of the work of the Corrosion of Metals Group. The value of the electrical capacitance method of measuring the rate of water uptake of a paint film on immersed metal has been further investigated with anticorrosive paints and an anti-fouling paint, and an apparatus has been constructed in which specimens can be subjected to controlled amounts of spray solutions, infra-red and ultra-violet radiations. Studies of the mechanism of corrosion inhibition by * Department of Scientific and Industrial Research. Report of the Chemistry Research Board, with the Rcport of the Director of the plates. (Iondon: H.M.S.O., 1953.) 4s. 6d. net. potassium chromate and sodium benzoate using radioactive tracer techniques indicate that the former is more firmly held by the metallic surface. Bacteriological examination of a clay soil in which the expected attack on buried pipes had not occurred revealed the presence of a species of Actinomyces toxic to sulphate-reducing bacteria. Examination of a waterlogged clay soil from a site at Hungate, York, in which ancient buried iron particles were excellently preserved in spite of the presence of sulphate-reducing bacteria, anaerobic conditions and the appropriate $p \mathrm{H}$ range for bacterial activity, showed that the activity of the bacteria was suppressed by concentrations of tannin of 0.01 per cent and upwards. In conjunction with the British Iron and Steel Research Association, an inquiry has been initiated into the incidence of buried water-pipe failure in Britain and the efficacy of cathodic protection. Other investigations have included a study of the effect of pressure on the rate of oxidation of copper at $100-250^{\circ} \mathrm{C}$. and the use of film-stripping and microchemical techniques in a study of the influence of surface condition on the low-temperature oxidation of mild steel, while an investigation of the effect of small amounts of salts and particles left on metal surfaces subject to different treatments in metal-finishing processes has shown that blistering of paint on sheet-steel articles may be caused by salt contamination of metal surfaces arising in treatments prior to painting. The importance of humidity in the corrosion of steel has been confirmed in tests carried out in collaboration with the Institute of Petroleum Protective Panel, and good protective value has been obtained by temporary protective coatings in which corrosion inhibitors are incorporated in thixotropic suspensions of inorganic earths : although soft and easily removed when no longer required, these coatings do not flow from the protected surfaces on storage.

The Inorganic Group has completed its work on the elimination of arsenical impurities from germanium; further work has been carried out on the production of dicalcium phosphate from phosphate rock by the action of nitric acid followed by ammoniation, and studies of the action of sulphuric acid on an apatite from Uganda indicate that the apatite can be fairly readily converted to phosphoric acid provided the concentration of the sulphuric acid is carefully controlled. The study of the reaction between ferric oxide and ammonium sulphate has been continued; a search was commenced for possible sources of selenium from waste materials, and spectrochemical methods for detecting and estimating this element were being sought, as well as methods for determining phosphorus in organic compounds which can be applied to the determination of this element in ionexchange resins. In collaboration with the Radiochemical Group, the carrier technique, used for the micro-estimation of thorium, has been adapted to the direct determination of tantalum and niobium separately in ores. The chromatographic process for the separation of these metals that has been worked out by the Radiochemical Group has proved simple and accurate for a wide variety of products, while the quantitative separation of palladium, platinum, rhodium and iridium by a chromatographic process has been practically completed, and preliminary experiments have shown that bis. muth can be separated chromatographically from a solution containing nitric acid. Extension of the work on the adsorption and elution of complex cyanides of gold, copper and iron with 'Amberlite 
IRA 400' resin to the complex cyanides of nickel, cobalt, zinc and silver has led to the development of a method for the separation and recovery of these metals from solutions derived from the cyanidation of auriferous ores. New equipment constructed during the year includes apparatus for determining automatically the life of ion-exchange resins on continuous re-cycling with different solutions, and an automatic scanning device for filter-paper strips on which the separation of metallic salts containing radioactive tracers has been effected. The device provides a permanent quantitative record of the activity distribution. A scintillation counter has also been devised consisting essentially of a lead and brass housing for a photomultiplier with a heavy brass slide arranged so that a small silica cell can be brought easily and accurately in front of the photomultiplier cathode.

Some changes were made in the organization of the Organic Group during the year: the two Organic Intermediates Sections were amalgamated, and a new Standard Samples Section split off from the Purification and Measurements Section. Work on the introduction of functional groups into polystyrene resins through the chloromethylation reaction will in future be continued in the High Polymers Group, but the Organic Intermediates Section will continue to prepare substances that by polymerization or condensation will furnish new resins containing functional groups. An initial study of stearic acid containing palmitic acid by the differential vapour. pressure method, using an apparatus with mercury as the manometric liquid and a tap-less device for pressure equalization, showed that as little as 0.1 per cent of palmitic acid could be estimated. Measurements of the vapour pressures of pyridine bases continued, and the purification of iso-octane, methylcyclopentane, methylcyclohexane, ethylbenzene and $o$ cresol has been followed spectroscopically. A method of estimating isonicotinic acid in the presence of nicotinic, picolinic and dipicolinic acids has been developed in which a Spekker absorptiometer is used with an Ilford filter 604. Quantitative analyses have been made by infra-red absorption spectroscopy of mixtures of picolines, $2: 6$-butidines and 2-ethylpyridine. In collaboration with the National Physical Laboratory, the Organic Group has made progress in a programme for determining the heats of combustion of organic compounds by improvements in chemical technique and in the calorimeter, and the heats of combustion of four pyridine bases have been measured at $25^{\circ} \mathrm{C}$. under standard conditions. The isotope dilution method has been applied to the determination of naphthalene in a high-temperature coal tar and in the evaluation of the efficiency of naphthalene-recovery plant. A study of the mechanism of the Kolbe-Schmitt reaction has been commenced, and the benzoin reaction with terephthaldehyde has been reinvestigated. Attempts have been made to prepare selective ion-exchange resins of well-defined constitution by introducing suitable functional groups into polymers. The addition of carbon monoxide, acetylene and $\alpha$-picoline has brought the list of standard substances available for distribution as reference specimens to thirty-six items, and the temperature and pressure of acetylene at its triple point have been determined.

In view of the outstanding performance of polyvinyl alcohol films as semi-permeable membranes in non-aqueous systems and the specific recommendations of the High Polymers Committee that studies on the fundamental factors controlling the semipermeability of polymer films should be initiated and that membranes suitable for use in aqueous systems should be investigated, the effort of the High Polymers Group devoted to work on membranes has been increased. In the absence of additional staff, it has been necessary to stop work on covalent reactions of functional groups in polymers and to reduce that on ion exchange. The major items in the research programme of the Group are new studies on the ion-exchange and allied properties of polymers and studies on the semi-permeability of polymer films : with both topics much attention is being given to possible industrial applications of new materials or processes developed during the work. The programme of research on the use of surface-sulphonated polystyrene in ion-exchange chromatography has been completed, and work was commenced on the preparation of insoluble resins containing functional groups capable of reactions other than ion exchange. Investigation of the applications of polyvinyl alcohol membranes has shown that these membranes considerably extend the scope and accuracy of somatic pressure measurements on polymer solutions, and their impermeability to solute and ready transfer of solvent permit the use of simple unsymmetrical osmometers.

The Microbiology Group has intensified its fundamental investigations on sulphate-reducing bacteria. These have included studies of the hydrogenase activity of Desulphovibrio desulphuricans, of its carbon metabolism, including the pyruvate metabolism by which certain strains can grow without sulphate, its variability and its viability. Investigations of the formation of sulphide in the water bottoms of petrolstorage tanks led to the recommendation that the water should be changed frequently and sodium chlorate added where necessary, as this inhibits both sulphate reducers and the corrosion of steel. A continuous method for the cultivation of sulphatereducing bacteria is being employed by a team from the Chemical Research Laboratory at the Microbiological Research Department, Porton, of the Ministry of Supply, and a marked increase in the rate of sulphate-reduction has been achieved by the use of a suitable nutrient medium. Further development of the microbiological production of sulphur depends largely upon the availability of adequate supplies of suitable fermentable wastes as sources of carbon. The National Collection of Industrial Bacteria now maintains 620 strains, of which 52 were added during the year.

On the advice of the Pure Metals Committee, nickel, rhenium, thallium and titanium have been added to the stock of high-purity metals. Investigations on the oxidation of steel at moderately high temperatures have been commenced with special reference to the possible improved resistance of steels for boiler superheater tubes, and advice on the control of corrosion in heat-exchange systems resulted in successful treatment of a system at the Atomic Energy Research Establishment, Harwell, and of cooling coils in fermenter vessels used in the manufacture of penicillin and streptomycin. Advice has also been given on the choice of materials for the construction of a water-filtration plant in Australia, for heating coils in oil tankers and for a new sewerage scheme in Lancaster, and on the protection of wharf steelwork at Kuwait in the Persian Gulf and the prevention of corrosion in lining pipes in artesian wells in Madras. 